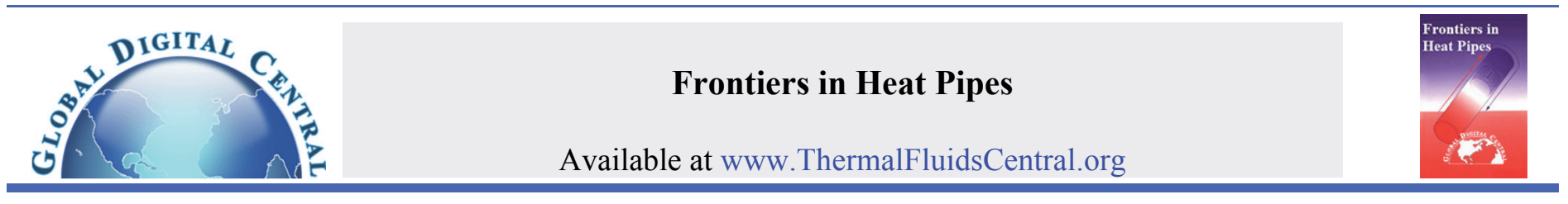

\title{
AN EXPERIMENTAL INVESTIGATION OF HEAT TRANSFER CAPABILITY AND THERMAL PERFORMANCE OF CLOSED LOOP PULSATING HEAT PIPE WITH A HYDROCARBON AS WORKING FLUID
}

\author{
Roshan D. Bhagat ${ }^{*}$, Kiran M. Watt \\ Department of Mechanical Engineering, Prof. Ram Meghe Institute of Technology and Research, Badnera-Amravati, Maharashtra, 444701, India
}

\begin{abstract}
An experimental investigation of closed loop pulsating heat pipes (CLPHPs) with a hydrocarbon as working fluid determine the effect of heat transfer and overall system performance at a given constrained dimensional heat source. The experimental investigation included start-up time and temperature, the average, minimum, and maximum evaporator temperature during its operation, the overall heat transfer capability, and the overall thermal resistance of the system, also the behaviour of CLPHP under different heat inputs and with the different working fluids. To achieve the goal the experimental setup is fabricated and tested with two different working fluids Acetone and Methanol with the filling ratio of $60 \%$. This work provides the detailed discussion on the thermal performance of CLPHP with Acetone and Methanol as working fluid and behaviour of CLPHP at different heat inputs.
\end{abstract}

Keywords: Thermal resistance, pulsating, working fluid, heat input.

\section{INTRODUCTION}

The Pulsating Heat Pipe (PHP) is a two-phase passive heat transfer device proposed and patented by Akachi (1990). The closed loop pulsating heat pipe (CLPHP) is a heat exchanger with very high thermal conductivity. It was invented to meet the requirement for smaller heat transfer device. It can transfer sufficient heat for heat dissipation applications in modern electronics devices. The CLPHP is made of a long copper capillary tube, bent into an undulating tube and connected at the ends to form a closed loop with no internal wick structure.

Khandekar and Groll (2003) conducted experiments on a PHP made of copper capillary tube of $2 \mathrm{~mm}$ inner diameter for three different working fluids viz. water, ethanol and R-123. The PHP was tested in vertical (bottom heat mode) as well as horizontal orientation and indicated that, a 100\% filled PHP (not working in the pulsating mode but instead as a single-phase buoyancy-induced thermosyphon) is thermally better performing than a partially filled pulsating mode device under certain operating conditions.

Khandekar and Groll (2004) studied that, complete stop-over is in the loop occurs more frequently for filling ratio $<50 \%$ coupled with low heat input power. Stop-over phenomenon has also been observed for higher filling ratios. The 'self-sustained' oscillating character is then lost, such a behavior has never been reported for multi-turn PHPs because of alternating periods in which bubble plugs are moving rapidly (activity phase) and 'stopping' (static phase).

Khandekar et al. (2009) observed that the quasi-steady state corresponding to best thermal performance consists of continuous unidirectional flow circulations, while the state corresponding to poor thermal performance is characterized by the intermittent bidirectional flow reversals. Oscillating Taylor bubble flows require immediate attention (Khandekar et al., 2010), unless the nuances of oscillatory confined bubbles in small capillaries is well discerned, the net pressure drop correlations for a PHP cannot be exhaustively constructed.

Dadong and Cui (2010) indicated that the thermal resistance decreases with the increase of the heating power at the same filling ratio. For the pure working fluid PHPs, the thermal resistance is decreases in the sequence of water, ethanol, Methanol and Acetone.

Narasimha et al. (2012) studied that, at atmospheric condition; the saturation temperature is higher compared to evacuated situation. Thus more liquid phase exists in the tube with a consequent increase in the heat transfer.

Charoensawan et al. (2003) indicated that in vertical orientation for the $2.0 \mathrm{~mm}$ devices, water filled devices showed higher performance as compared to R-123 and ethanol. Whereas in $1.0 \mathrm{~mm}$ devices, R-123 and ethanol filled devices showed comparable performance but water showing very poor results.

Bhagat R.D., Watt K.M., (2015) observed that the Acetone as working fluid has higher value of bond number and lesser thermal resistance whereas Methanol has higher thermal resistance and lower value of bond number. So the working fluid with higher value of bond number gives higher thermal performance than the working fluid with lower value of bond number.

Working fluid is partially filled in the tube. The CLPHP has a condenser, evaporator and adiabatic section. As any other two phase passive thermal control device, heat is acquired from the source through the evaporator section transferring it to the working fluid where the slug/plug pumping action will be generated. The working fluid then flows by the adiabatic section towards the condenser section. On a closed loop configuration, the working fluid is allowed to circulate and after 
being condensed and returns to the evaporator section to complete the loop. The tube is evacuated and consequently partially filled with working fluid. Since an inner diameter of the tube is very small and then meets a capillary scale, the inside working fluid forms into liquid slugs alternating with vapour plugs along the entire length of the tube.

The pipe is first evacuated and then filled partially with a working fluid. If the diameters of CLPHP is not too large, the working fluid distributes itself into an arrangement of liquid slugs separated by vapour bubbles. One end of this tube bundle receives heat transferring it to the other end by a pulsating action of the liquid-vapour/slug-bubble system. The liquid and vapour slug/bubble transport is caused by the thermally induced pressure pulsations inside the device and no external mechanical power is required. The type of working fluid and the operating pressure inside the pulsating heat pipe depends on the operating temperature of the heat pipe. The region between evaporator and condenser is adiabatic. The heat is transfer from evaporator to condenser by the means of pulsating action of vapour and liquid slug.

The objective of the present work is to study the CLPHP with hydrocarbon as working fluid with three turns in the evaporator section and two small turn and one large turn in condenser section. In the present work thermal performance of CLPHP with Acetone and Methanol as working fluid is investigated at different heat inputs having filling ratio of $60 \%$. Also the effect of water bath temperature on evaporator and condenser temperature of CLPHP with Acetone and Methanol as working fluid is studied.

\section{EXPERIMENTATION}

The purpose of this initiative was to combine fluid dynamics and heat transfer to create a device capable of transferring heat within the small distance. The first phase focused on fabricating the apparatus and performing the initial testing to gain preliminary insight into its functionality. In addition to successfully transferring heat from heat source to the heat sink, this task provided an opportunity for experimental learning and device creation and targeted design through engineering principles.

\subsection{Setup Description}

\subsubsection{Working Fluid}

Working fluid is the most important factor that significantly influence on the thermal performance of CLPHP. Hydrocarbon working fluid involves Acetone, Methanol, Ethanol, Methane and Pentane. Experimental setup consists of CLPHP with Acetone and Methanol as working fluid. The boiling point of Methanol is $64^{\circ} \mathrm{C}$ and Acetone $57^{\circ} \mathrm{C}, 60 \%$ filling ratio has been used for Acetone and Methanol.

\subsubsection{Copper Tube}

Compatibility of copper with Acetone and Methanol as working fluid made it possible to use copper tube for preparing the experimental setup. The inner diameter of copper tube is $2 \mathrm{~mm}$ and outer diameter of $3 \mathrm{~mm}$. The small diameter is chosen so as to have capillary action. The copper tube is bent into three small turns in evaporator section and two small turns and one large turn in condenser section.

\subsubsection{Digital LASER Thermometer}

For measuring the evaporator temperature i.e. from $T_{1}$ to $T_{6}$ and condenser temperature from $T_{7}$ to $T_{12}$ as shown in Fig. 1 the digital LASER thermometer is used. The digital LASER thermometer provides to flexibility to measure the temperature over the entire length of the copper tube.

\subsubsection{Evaporator Tank}

The evaporator tank design to the dimension of 8 inch $\times 6$ inch $\times$ 4 inch, so as to occupy the heating element and to have sufficient amount of water inside the evaporator tank for heating the copper tube, with the water bath heating is done.

\subsubsection{Condenser Tank}

The surface area of copper tube inside the condenser tank should be higher than the surface area of copper tube inside the evaporator tank hence the dimension of condenser tank is taken as 12 inch $\times 3$ inch $\times$ 4 inch. The condenser tank should hold sufficient water so as to have heat rejection by the working fluid through the copper tube and to have condensation of working fluid.

\subsubsection{Coil Heater}

The coil heater with capacity of $500 \mathrm{Watt}$ is used to heat the water inside the evaporator tank.

\subsubsection{Temperature Indicator for Water Bath in Evaporator}

For measuring the water bath temperature inside the evaporator tank, temperature indicator is used to monitor the temperature of water bath so as to prevent the excessive heating of water which may cause the dry out of working fluid in the copper tube.

\subsubsection{Variable AC Power Supply}

For changing the heat inputs to the coil heater variable AC power supply is used. 0-240 VAC can be adjusted with the help of dimmerstat. Digital voltmeter and ammeter are connected to show the voltage and current reading.

\subsubsection{Control Panel}

Digital voltmeter, ammeter and water bath temperature indicator are mounted on the control panel.

\subsubsection{Tank Material}

Evaporator and condenser tank are prepared with acrylic. Acrylic is non conducting material and heat loss to the surrounding is kept minimum. Magnabond instant adhesive is used for preparing leak proof tank.

\subsection{EXPERIMENTATION AND TESTING OF CLPHP WITH ACETONE AND METHANOL AS WORKING FLUID.}

The experimentation performed on CLPHP by heating the water bath with the help of coil heater. The heat inputs to the coil heater can be adjusted by using 0 to 240 VAC power supply. Heat transfer by convection takes place from water to the copper tube and heat is conducted through the copper tube, this heat is now transferred to the working fluid present inside the copper tube. This working fluid reject heat to the water available in the condenser tank by sensible heat of liquid and latent heat of vapour.

The evaporator temperature $T_{1}$ to $T_{6}$ and condenser temperature $T_{7}$ to $T_{12}$ measured with the help of digital LASER thermometer. The twelve temperature points are as shown in the Fig. 1. The thermal resistance of CLPHP was calculated for the given heat inputs by taking the temperature difference between the evaporator and condenser and dividing it by the heat input. 


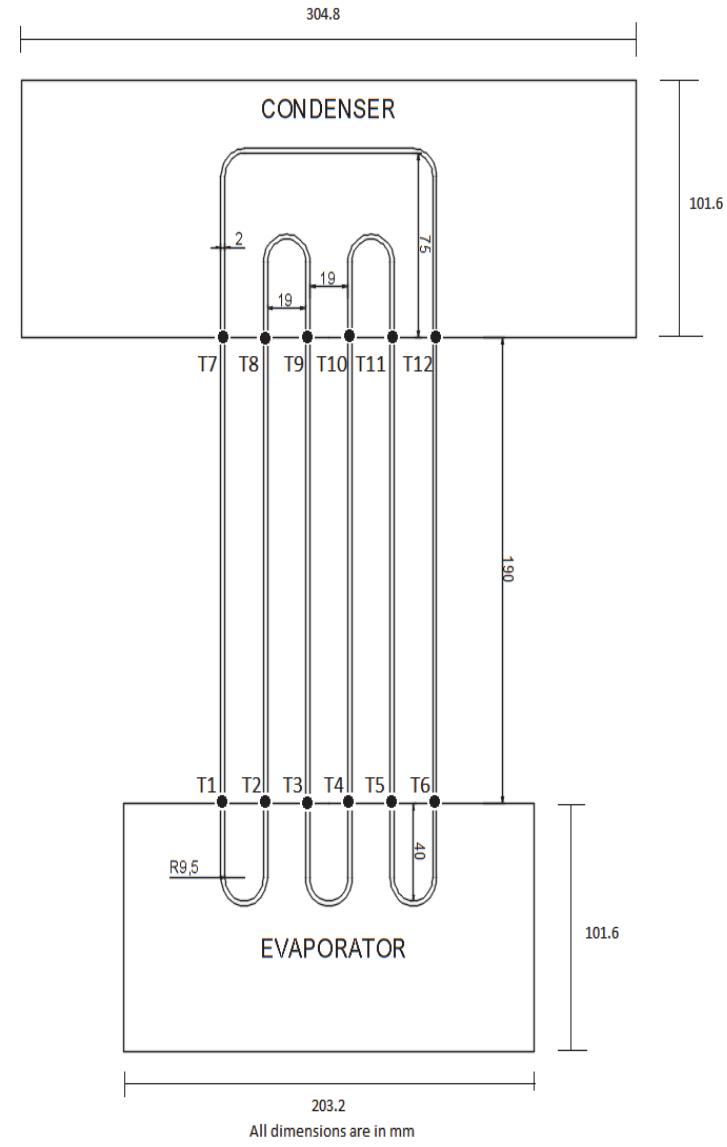

Fig. 1 Specification of experimental setup of closed loop pulsating heat pipe

\subsection{CALCULATION}

The thermal resistance of CLPHP can be calculated by using the following equations,

$$
\begin{gathered}
R_{\text {thermal }}=\frac{T_{e}-T_{c}}{Q} \\
R_{\text {thermal }}-\text { Thermal resistance } \\
T_{e}-\text { Average evaporator temperature } \\
T_{c}-\text { Average condenser temperature }
\end{gathered}
$$

Table 1 Thermal resistance of CLPHP with Acetone and Methanol as working fluid

\begin{tabular}{|c|c|c|c|c|c|c|c|}
\hline S.N. & $\begin{array}{c}\text { Heat } \\
\text { Input }\end{array}$ & $\begin{array}{c}\text { Average } \\
\text { Evaporator } \\
\text { Temperature of } \\
\text { Acetone }\end{array}$ & $\begin{array}{c}\text { Average } \\
\text { Condenser } \\
\text { Temperature } \\
\text { of Acetone }\end{array}$ & $\begin{array}{c}\text { Average } \\
\text { Evaporator } \\
\text { Temperature of } \\
\text { Methanol }\end{array}$ & $\begin{array}{c}\text { Average } \\
\text { Condenser } \\
\text { Temperature } \\
\text { of Methanol }\end{array}$ & $\begin{array}{c}\text { Thermal } \\
\text { Resistance of } \\
\text { Acetone }\end{array}$ & $\begin{array}{c}\text { Thermal } \\
\text { Resistance of } \\
\text { Methanol }\end{array}$ \\
\hline $\mathbf{1}$ & 1 & 25.98333333 & 25.93333333 & 24.83333333 & 23.91666667 & 0.05 & 0.916666667 \\
\hline $\mathbf{2}$ & 4 & 25.83333333 & 25.81666667 & 24.48333333 & 23.76666667 & 0.004166667 & 0.179166667 \\
\hline $\mathbf{3}$ & 9.3 & 25.8 & 25.46666667 & 24.9 & 19.81666667 & 0.035842294 & 0.546594982 \\
\hline $\mathbf{4}$ & 16.4 & 26.2 & 25.43333333 & 25.31666667 & 24 & 0.046747967 & 0.080284553 \\
\hline $\mathbf{5}$ & 16.4 & 26.85 & 25.51666667 & 25.75 & 24.11666667 & 0.081300813 & 0.099593496 \\
\hline $\mathbf{6}$ & 26.5 & 26.96666667 & 25.51666667 & 26.71666667 & 24.1 & 0.054716981 & 0.098742138 \\
\hline $\mathbf{7}$ & 26.5 & 27.63333333 & 25.45 & 27.53333333 & 24.3 & 0.082389937 & 0.122012579 \\
\hline $\mathbf{8}$ & 26.5 & 28.25 & 25.56666667 & 27.83333333 & 24.26666667 & 0.101257862 & 0.134591195 \\
\hline
\end{tabular}

Average evaporator temperature

is calculated by using the equation

$$
T_{e}=\frac{T_{1}+T_{2}+T_{3}+T_{4}+T_{5}+T_{6}}{6}
$$

\section{Average condenser temperature}

is calculated by using the equation

$$
T_{c}=\frac{T_{7}+T_{8}+T_{9}+T_{10}+T_{11}+T_{12}}{6}
$$

\section{RESULT AND DISCUSSION}

\subsection{RESULT}

It was observed during the experimentation that as the water bath temperature increases there is increase in evaporator and condenser temperature of CLPHP. With increase in the heat input the thermal resistance of CLPHP decreases. For Methanol it was observed that the thermal resistance decreases with increase in heat input. For Acetone it was observed that the thermal resistance of CLPHP first increases then decreases. After comparing the thermal resistance of CLPHP with Acetone and Methanol as working fluid, it was observed that at the same heat input and the filling ratio of $60 \%$ Acetone has lesser thermal resistance than Methanol. CLPHP with Acetone as working fluid gives higher thermal performance.

Also it was observed from the table 1 that if the heat input is kept constant for some duration the thermal resistance is increase as shown in table 1 for the heat input of 26.5 watt initially the thermal resistance was 0.0547 for Acetone and 0.09874 for Methanol but this thermal resistance is increase if we observed the last reading of 26.5 watt the thermal resistance was found to be 0.13548 for Acetone and 0.1987 for Methanol. This shows that if the heat input is kept constant for longer period of time the thermal resistance of both working fluid increases. But when the heat input is change as if we observed the reading from 26.5 watt to 37.8 watt, there is sudden drop in the thermal resistance for Acetone from the value of 0.135 to 0.1062 and for Methanol drop in the thermal resistance from 0.1987 to 0.1419 . When the heat input was not kept constant as per the reading at 221.85 watt to 360.75 watt, sudden drop in the thermal resistance was observed for Acetone and Methanol. The thermal resistance of Acetone was change from 0.1449 to 0.09 and for Methanol the thermal resistance was change from 0.1667 to 0.1097 . At negligible heat input of 1 watt, the thermal resistance of Methanol found to be very high as depicted in Fig. 3. 


\begin{tabular}{|c|c|c|c|c|c|c|c|}
\hline 9 & 26.5 & 28.16666667 & 25.3 & 28.81666667 & 24.2 & 0.108176101 & 0.174213836 \\
\hline 10 & 26.5 & 28.61666667 & 25.45 & 29.48333333 & 24.71666667 & 0.119496855 & 0.179874214 \\
\hline 11 & 26.5 & 29.06666667 & 25.46666667 & 29.7 & 24.43333333 & 0.135849057 & 0.198742138 \\
\hline 12 & 37.8 & 29.36666667 & 25.35 & 29.61666667 & 24.25 & 0.106261023 & 0.141975309 \\
\hline 13 & 37.8 & 29.76666667 & 25.066666667 & 30.4 & 24.38333333 & 0.124338624 & 0.159171076 \\
\hline 14 & 37.8 & 30.11666667 & 25.01666667 & 30.55 & 24.43333333 & 0.134920635 & 0.161816578 \\
\hline 15 & 37.8 & 30.28333333 & 25.06666667 & 30.93333333 & 24.78333333 & 0.138007055 & 0.162698413 \\
\hline 16 & 37.8 & 30.51666667 & 25.05 & 31.2 & 24.55 & 0.144620811 & 0.175925926 \\
\hline 17 & 51.1 & 30.91666667 & 25.05 & 31.4 & 24.76666667 & 0.114807567 & 0.129810828 \\
\hline 18 & 51.1 & 31.4 & 25.05 & 31.7 & 24.7 & 0.124266145 & 0.136986301 \\
\hline 19 & 51.1 & 31.7 & 25.06666667 & 32.5 & 24.86666667 & 0.129810828 & 0.1493803 \\
\hline 20 & 51.1 & 32.23333333 & 25.066666667 & 32.38333333 & 24.91666667 & 0.14024788 & 0.146118721 \\
\hline 21 & 51.1 & 32.26666667 & 25.06666667 & 33 & 25 & 0.140900196 & 0.156555773 \\
\hline 22 & 51.1 & 32.91666667 & 25.11666667 & 33.32166667 & 24.96666667 & 0.152641879 & 0.163502935 \\
\hline 23 & 67.2 & 33.11666667 & 25.3 & 33.83333333 & 25.1 & 0.116319444 & 0.129960317 \\
\hline 24 & 67.2 & 33.9 & 25.41666667 & 34.25 & 25.16666667 & 0.126240079 & 0.135168651 \\
\hline 25 & 67.2 & 34.21666667 & 25.46666667 & 34.75 & 25.15 & 0.130208333 & 0.142857143 \\
\hline 26 & 67.2 & 34.53333333 & 25.55 & 35.05 & 25.38333333 & 0.133680556 & 0.143849206 \\
\hline 27 & 67.2 & 34.75 & 25.48333333 & 35.51666667 & 25.38333333 & 0.137896825 & 0.150793651 \\
\hline 28 & 84.6 & 33.53333333 & 25.83333333 & 35.53333333 & 25.5 & 0.091016548 & 0.118597321 \\
\hline 29 & 84.6 & 35.5 & 25.81666667 & 36.7 & 25.45 & 0.114460205 & 0.132978723 \\
\hline 30 & 84.6 & 36.33333333 & 26.066666667 & 37.63333333 & 25.58333333 & 0.121355398 & 0.142434988 \\
\hline 31 & 84.6 & 36.76666667 & 26.15 & 37.93333333 & 25.61666667 & 0.125492514 & 0.145587076 \\
\hline 32 & 84.6 & 37.15 & 26.266666667 & 38.56666667 & 25.86666667 & 0.128644602 & 0.150118203 \\
\hline 33 & 84.6 & 37.35 & 26.5 & 39.13333333 & 26.01666667 & 0.128250591 & 0.155043341 \\
\hline 34 & 84.6 & 37.71666667 & 26.5 & 39.5 & 26.11666667 & 0.132584712 & 0.158195429 \\
\hline 35 & 104 & 38.58333333 & 26.51666667 & 40.46666667 & 26.05 & 0.116025641 & 0.138621795 \\
\hline 36 & 104 & 38.8 & 26.6 & 41.96666667 & 26.16666667 & 0.117307692 & 0.151923077 \\
\hline 37 & 104 & 39.6 & 26.78333333 & 43.75 & 26.4 & 0.123237179 & 0.166826923 \\
\hline 38 & 104 & 40.15 & 27.11666667 & 44.9 & 26.56666667 & 0.125320513 & 0.176282051 \\
\hline 39 & 104 & 42.51666667 & 27.13333333 & 46.03333333 & 26.88333333 & 0.147916667 & 0.184134615 \\
\hline 40 & 104 & 42.58333333 & 27.1 & 46.2 & 26.93333333 & 0.148878205 & 0.18525641 \\
\hline 41 & 104 & 43.9 & 27.28333333 & 46.96666667 & 27.03333333 & 0.159775641 & 0.191666667 \\
\hline 42 & 126.5 & 44.85 & 27.26666667 & 49.18333333 & 27.18333333 & 0.138998682 & 0.173913043 \\
\hline 43 & 126.5 & 46.9 & 27.28333333 & 50.78333333 & 27.28333333 & 0.155072464 & 0.185770751 \\
\hline 44 & 126.5 & 48.78333333 & 27.46666667 & 52.26666667 & 27.33333333 & 0.168511199 & 0.197101449 \\
\hline 45 & 126.5 & 50.16666667 & 27.55 & 52.6 & 27.53333333 & 0.178787879 & 0.198155468 \\
\hline 46 & 126.5 & 50.95 & 27.75 & 53.4 & 27.56666667 & 0.183399209 & 0.204216074 \\
\hline 47 & 163.75 & 51.53333333 & 28.15 & 54.35 & 27.33333333 & 0.142798982 & 0.164987277 \\
\hline 48 & 163.75 & 52.43333333 & 28.666666667 & 50.76666667 & 27.35 & 0.145139949 & 0.143002545 \\
\hline 49 & 163.75 & 54.31666667 & 28.83333333 & 60.83333333 & 27.96666667 & 0.15562341 & 0.200712468 \\
\hline 50 & 163.75 & 55.05 & 29.4 & 60.46666667 & 28.1 & 0.156641221 & 0.197659033 \\
\hline 51 & 163.75 & 56.36666667 & 29.63333333 & 60.16666667 & 28.05 & 0.163256997 & 0.196132316 \\
\hline 52 & 163.75 & 56.93333333 & 29.75 & 60.91666667 & 28.1 & 0.166005089 & 0.200407125 \\
\hline 53 & 163.75 & 58.35 & 29.96666667 & 61.46666667 & 28.23333333 & 0.173333333 & 0.202951654 \\
\hline 54 & 163.75 & 58.71666667 & 30.48333333 & 62.85 & 28.95 & 0.172417303 & 0.207022901 \\
\hline 55 & 190.35 & 59.03333333 & 30.38333333 & 63.6 & 29.41666667 & 0.150512214 & 0.179581473 \\
\hline 56 & 190.35 & 59.76666667 & 30.35 & 64.33333333 & 30.35 & 0.154539883 & 0.178530777 \\
\hline 57 & 190.35 & 62.1 & 30.95 & 65 & 30.43333333 & 0.163645915 & 0.181595307 \\
\hline 58 & 190.35 & 62.36666667 & 30.73333333 & 66.23333333 & 29.06666667 & 0.166185098 & 0.195254356 \\
\hline 59 & 221.85 & 62.95 & 31.16666667 & 67.63333333 & 30.08333333 & 0.143264969 & 0.169258508 \\
\hline 60 & 221.85 & 63.76666667 & 31.61666667 & 67.91666667 & 30.93333333 & 0.144917737 & 0.16670423 \\
\hline 61 & 238.5 & 63.6 & 31.31666667 & 69.56666667 & 31.33333333 & 0.135359888 & 0.160307477 \\
\hline 62 & 285.45 & 65.1 & 32.03333333 & 70.6 & 31.73333333 & 0.115840486 & 0.136159281 \\
\hline 63 & 309.75 & 66.85 & 32.06666667 & 70.95 & 31.93333333 & 0.112294861 & 0.125961797 \\
\hline 64 & 360.75 & 68.65 & 32.61666667 & 71.76666667 & 32.18333333 & 0.0998845 & 0.10972511 \\
\hline
\end{tabular}




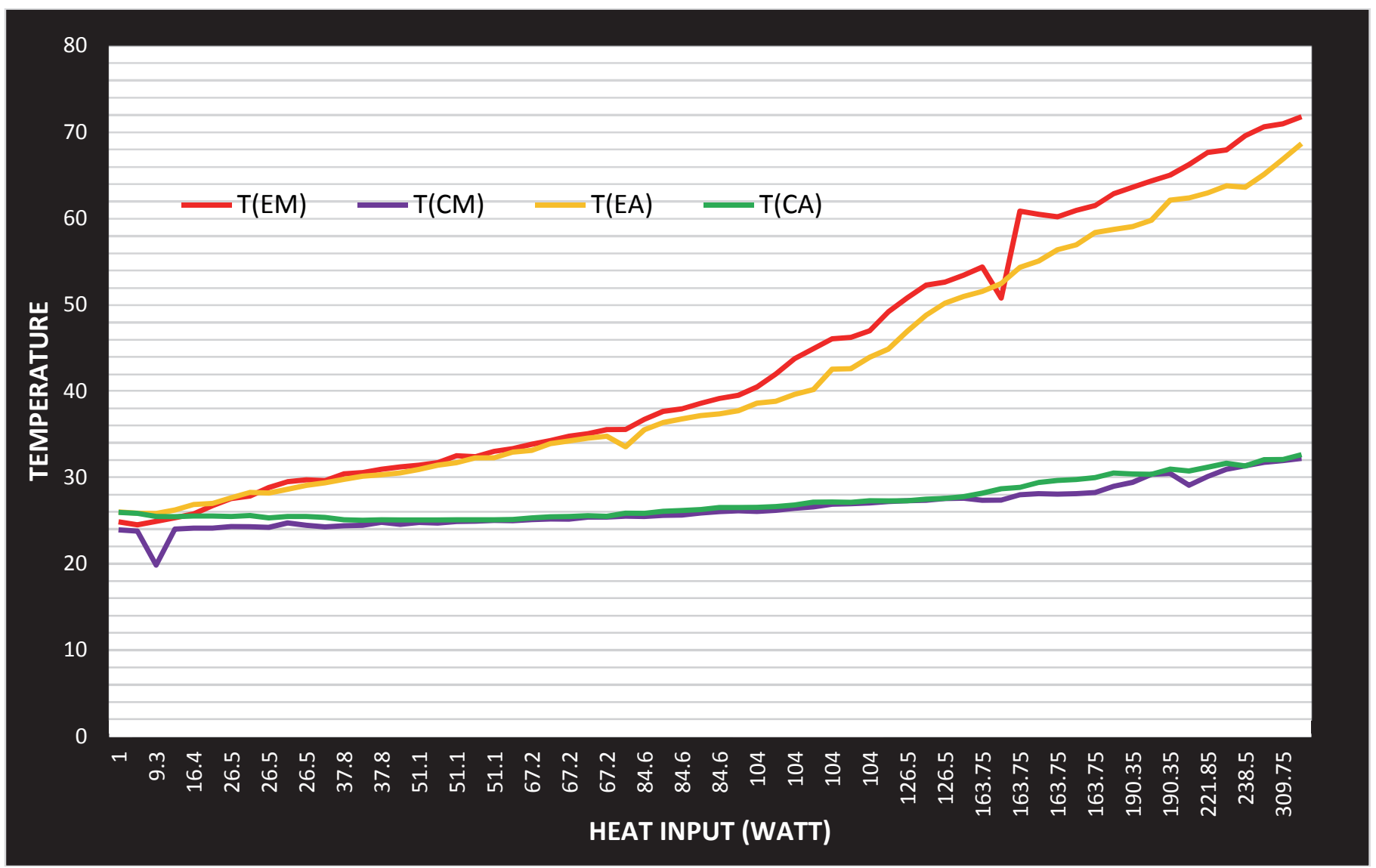

Fig. 2 Evaporator and condenser temperature of CLPHP with Acetone and Methanol as working fluid

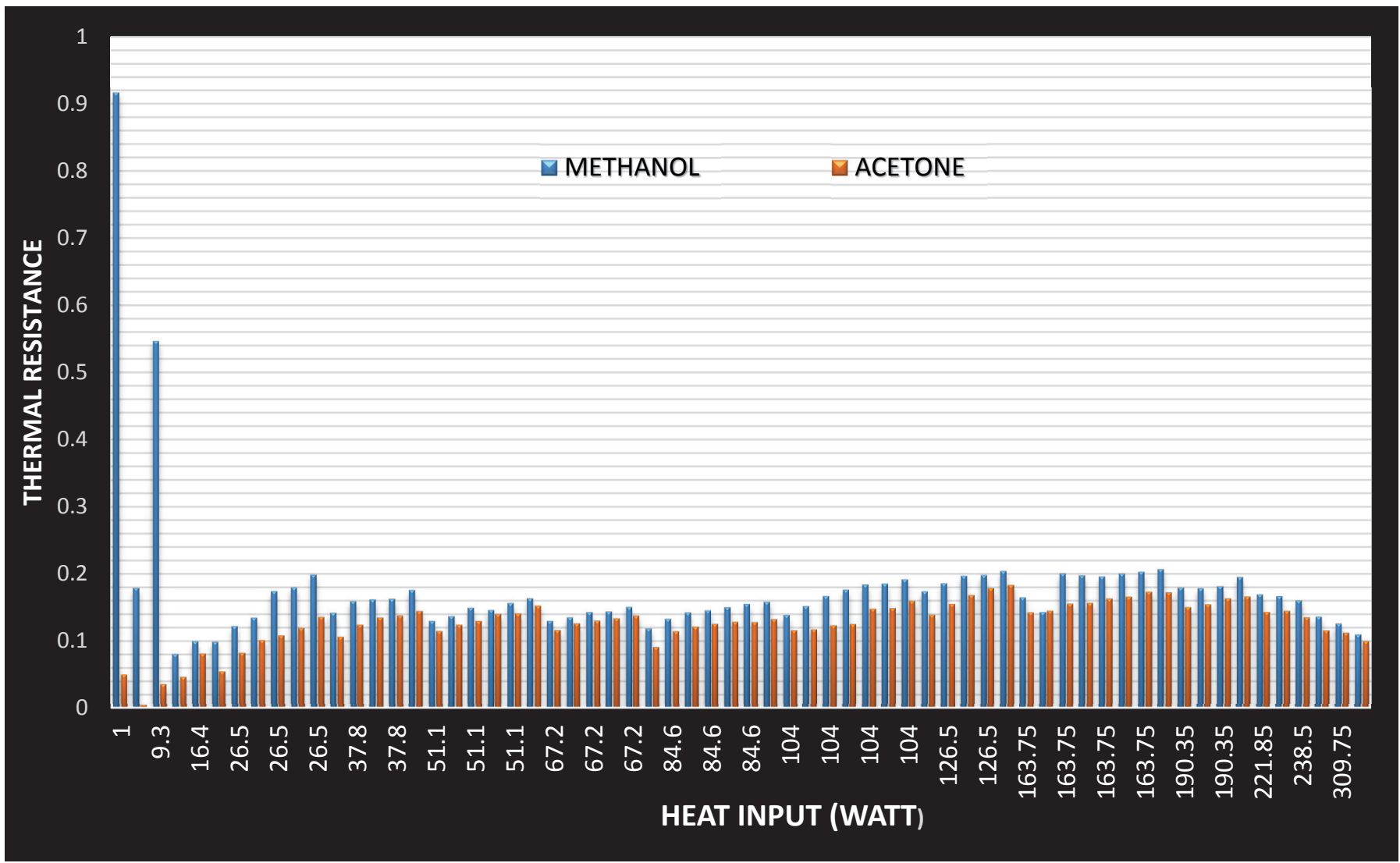

Fig. 3 Thermal resistance of CLPHP with Acetone and Methanol as working fluid 


\subsection{DISCUSSION}

The latent heat for Methanol is $1101 \mathrm{~kJ} / \mathrm{kg}$ while the latent heat for Acetone $523 \mathrm{~kJ} / \mathrm{kg}$, so the CLPHP with Acetone as working fluid can be used for lower heat application in the temperature range of 0 to 68.65 as shown in table 1, because excessive heat can cause the dry out of working fluid. Whereas, Methanol can be used for higher heat applications in the temperature range of 0 to 71.76 as shown in the table 1 the advantage associated with Acetone due to lower latent heat is that it required less heat for converting liquid into vapour. The working fluid with higher value of Bond number gives higher thermal performance than the working fluid with lower value of Bond number. Acetone has lesser thermal resistance and has higher Bond number, whereas Methanol has higher thermal resistance and lower Bond number.

The evaporator temperature increases more rapidly when both the working fluid reaches to their boiling point this can be observed from the Fig. 2 the evaporator temperature of Acetone and Methanol increases rapidly after heat input of 67.2 watt. And there is more difference in the evaporator temperatures for Acetone and Methanol after the heat input of 104 watt this is clearly observed from the Fig. 2. Whereas the condenser temperature remains nearly same for both working fluid till the heat input reaches to 163.75 watt but after that some difference can be observed up to the heat input of 238.5 watt as shown in Fig. 2.

\subsection{SOURCES OF ERRORS}

$>$ The temperature of tube from $T_{1}$ to $T_{12}$ is measured with the help of digital LASER thermometer, the accuracy of digital LASER thermometer depends on the distance to spot ratio. Hence, improper distance to spot ratio has possibility of creating errors while measurement of evaporator and condenser temperature.

$>$ For investigating the thermal performance of CLPHP with Acetone and Methanol as working fluid, the temperature should be noted at ambient condition, there could be errors while the observations obtained with different working fluids, if water bath temperature is not same in all experimentation.

$>$ Heat loss from water to the surrounding should be minimize to maximum possible extent to avoid deceptive evaporator and condenser readings.

$>$ Care should be taken to avoid excessive heat inputs which may cause drying out of working fluid in the tubes.

\section{CONCLUSION}

When water bath temperature increases, there is increase in the evaporator and condenser temperature of CLPHP. The condenser temperature increases more rapidly when the water bath temperature reaches to the boiling point of working fluid used in CLPHP. The thermal resistance of CLPHP decreases with increase in heat input. The thermal resistance of CLPHP with Acetone as working fluid is less as compared to thermal resistance of Methanol at same heat inputs and filling ratio of $60 \%$. Hence from the experimentation, it can be concluded that out of the two hydrocarbon working fluids, the thermal performance of Acetone is higher. CLPHP is a highly attractive heat transfer technology due to its excellent thermal performance, it is expected to meet the requirement for smaller heat transfer device which can transfer heat with minimum temperature difference.

\section{NOMENCLATURE}

$\begin{array}{ll}\text { CLPHP } & \text { Closed loop pulsating heat pipe } \\ \text { PHP } & \text { Pulsating heat pipe } \\ \text { V } & \text { Voltage } \\ \text { I } & \text { Current }\end{array}$

$\begin{array}{ll}\text { Q } & \text { Heat input } \\ \mathrm{T} & \text { Temperature } \text { in }^{0} \mathrm{C} \\ \mathrm{ID} & \text { Inner diameter } \\ \mathrm{OD} & \text { Outer diameter } \\ \mathrm{EM} & \text { Evaporator temperature of Methanol } \\ \mathrm{CM} & \text { Condenser temperature of Methanol } \\ \mathrm{EA} & \text { Evaporator temperature of Acetone } \\ \mathrm{CA} & \text { Condenser temperature of Acetone } \\ \mathrm{VAC} & \text { Variable AC supply } \\ \mathrm{Te} & \text { Average evaporator temperature } \\ \text { Tc } & \text { Average condenser temperature } \\ \text { Rtherm } & \text { Thermal resistance }\end{array}$

\section{REFERENCES}

H. Akachi, F. Polasek, P. Stulc, 1990, "Pulsating Heat Pipes," Proceedings of $5^{\text {th }}$ International Heat Pipe Symposium, Melbourne, Australia, pp. 208-217.

Khandekar S., Groll M., 2003, "On the Definition of Pulsating Heat Pipe," Proceedings of $5^{\text {th }}$ Minsk International Seminar (Heat Pipes, Heat Pumps and Refrigerators), Minsk, Belarus.

Dadong Wang, Xiaoyu. Cui, 2010, "Experimental Research on Pulsating Heat Pipe with Different Mixtures Working Fluids," the $21^{\text {st }}$ International Symposium on Transport Phenomena 2-5 November, Kaohsiung City, Taiwan.

Narasimha K. R., Sridhara S.N., Rajagopal M.S., Seetharamu K.N., 2012, "Influence of Heat Input, Working Fluid and Evacuation Level on the Performance of Pulsating Heat Pipe," Journal of Applied Fluid Mechanics, Vol. 5/2, pp. 33-42.

M. B. Shafii, A. Faghri, Y. Zhang, 2001, "Thermal Modeling of Unlooped and Looped Pulsating Heat Pipes," ASME Journal of Heat Transfer, 123, 1159-1172.

http://dx.doi.org/10.1115/1.1409266

Charoensawan P., Khandekar S. Groll M., 2004, "Closed Loop and Open Loop Pulsating Heat Pipes," Proceedings of $13^{\text {th }}$ International Heat Pipe Conference, Shanghai, China, pp. 21-25.

Khandekar S., Dollinger N., Groll M., 2003, "Understanding Operational Regimes of Closed Loop Pulsating Heat Pipes: An Experimental Study," Applied Thermal Engineering, 23, 707-719. http://dx.doi.org/10.1016/S1359-4311(02)00237-5

Groll M., Khandekar S., 2004, “An Insight into Thermo-Hydrodynamic Coupling in Closed Loop Pulsating Heat Pipes," International Journal of Thermal Sciences, 43, 13-20.

http://dx.doi.org/10.1016/S1290-0729(03)00100-5

Groll M., Khandekar S., 2002, "Pulsating Heat Pipes: A Challenge and Still Unsolved Problem in Heat Pipe Science," Proceedings of $3^{\text {rd }}$ International Conference on Transport Phenomena in Multiphase Systems, Kielce, Poland, pp. 35-44 (ISBN 83- 88906-03-8).

Arab M., Soltanieh M., Shafii M., 2012, "Experimental Investigation of Extra-Long Pulsating Heat Pipe Application in Solar Water Heaters," Experimental Thermal and Fluid Science, 42, 6-15. http://dx.doi.org/10.1016/j.expthermflusci.2012.03.006 
Khandekar S., Groll M., Charoensawan P., Terdtoon P., 2002, "Pulsating Heat Pipes: Thermo-Fluidic Characteristics and Comparative Study with Single Phase Thermosyphon," Proceedings of $12^{\text {th }}$ International Heat Transfer Conference, ISBN-2-84299-307-1, Vol. 4, pp. 459-464, Grenoble, France.

Charoensawan, P., Khandekar, S., Groll, M., Terdtoon, P., 2003 "Closed Loop Pulsating Heat Pipes- Part A: Parametric Experimental Investigations," Applied Thermal Engineering," 23(16), 2009-2020. http://dx.doi.org/10.1016/s1359-4311(03)00159-5

Khandekar, S., Charoensawan, P., Groll, M., Terdtoon, P., 2003, “Closed Loop Pulsating Heat Pipes- Part B: Visualization and Semi-Empirical Modeling," Applied Thermal Engineering, 23(16), 2021-2033, http://dx.doi.org/10.1016/s1359-4311(03)00168-6

Soponpongpipat, N., Sakulchangsatjatai, P., Kammuanglue, N., Terdtoon, P., 2009, "Investigation of the Start-up Condition of a Closed Loop Oscillating Heat Pipe," Heat Transfer Engineering, 30(8), 626642.

http://dx.doi.org/10.1080/01457630802656876

Zhang, Y., Faghri, A., 2002, "Heat Transfer in a Pulsating Heat Pipe with Open End," International Journal of Heat Mass Transfer, 45, 755-764.

http://dx.doi.org/10.1016/s0017-9310(01)00203-4

Shafii, M. B., Faghri, A., Zhang, Y., 2002, “Analysis of Heat Transfer in Unlooped and Looped Pulsating Heat Pipes," International Journal of Numerical Methods for Heat and Fluid Flow, 12(5), 585-609.

http://dx.doi.org/10.1108/09615530210434304

Tong B.Y., Wong T.N., Ooi K.T., 2001, “Closed Loop Pulsating Heat Pipe,” Applied Thermal Engineering, 21(18), 1845-1862.

http://dx.doi.org/10.1016/S1359-4311(01)00063-1

Kothandaraman C.P., Subramanyam S., 2014, Heat and Mass Transfer Data Book, Eight Edition, New Age International Publishers pp 189-190.

Amir Faghri, 2014, "Heat Pipes: Review, Opportunities and Challenges," Frontiers in Heat Pipes, 5, 1

http://dx.doi.org10.5098/fhp.5.1
Bhagat R.D., Watt K.M., 2014, “Closed Loop Pulsating Heat Pipe with Hydrocarbon as Working Fluid: A Review," International Journal of Science and Research, 3(10), 1576-1579.

Bhagat R.D., Watt K.M., 2015, "Effect of Dimensionless Number on Thermal Performance of Closed Loop Pulsating Heat Pipe: A Review," International Journal of Science and Research, 4(2), 486-491.

Bhagat R.D., Watt K.M., 2015, “An Experimental Investigation of Methanol Closed Loop Pulsating Heat Pipe at Variable Water Bath Temperature," International Journal of Science and Research (IJSR), 4(2), 1157-1161.

Bhagat R.D., Watt K.M., 2015. "Effect of Water Bath Temperature on Evaporator and Condenser Temperature of Closed Loop Pulsating Heat Pipe with Acetone as Working Fluid," International Journal for Research in Engineering and Technology, 4(2), 383-387.

http://dx.doi.org/10.15623/ijret.2015.0402050

Bhagat R.D., Watt K.M., 2015, "Experimentation to Predict the Thermal Performance of Closed Loop Pulsating Heat Pipe with Acetone and Methanol as Working Fluid," International Journal for Research in Engineering and Technology, 4(4), 23-27.

http://dx.doi.org/10.15623/ijret.2015.0404005

Bhagat R.D., Watt K.M., 2015, "Performance Investigation of Closed Loop Pulsating Heat Pipe with Acetone as Working Fluid," International Journal for Research in Engineering and Technology, 4(4), 1-4. http://dx.doi.org/10.15623/ijret.2015.0404001

Bhagat R.D., Watt K.M., 2015, "Performance Investigation of Closed Loop Pulsating Heat Pipe with Methanol as Working Fluid," Proceedings of Mechanical Engineering Post Graduate Conference at PRMIT \& R Badnera-Amravati, MEPCON-2015. International Journal of Innovative and Emerging Research in Engineering, Volume 2, and Special Issue 1, pp. 57-61.

Bhagat R.D., Watt K.M., 2015, "Effect of Bond Number on Thermophysical Properties of Working Fluid used in Closed Loop Pulsating Heat Pipe: A Review," International Journal of Science and Research (IJSR), 4(9), 544-551. 